\title{
Discharge against medical advice from neurology wards of a teaching hospital: A prospective observational study
}

\author{
Akshay Navalkishor Lakhotia, Ajoy Sodani*, Mukesh Dube, Kapil Telang, Rahul Jain, Sunil Athale \\ Department of Neurology, Sri Aurobindo Medical College \& P.G. Institute, Indore, 453555, India
}

\section{A R T I C L E I N F O}

\section{Keywords:}

Leave against medical advice

DAMA

DAMA in neurology

AMA

Determinants of AMA

\begin{abstract}
A B S T R A C T
Background: Factors associated with risk with leaving hospital against medical advice (AMA) in neurology patients is unknown.

Objective: To determine prospectively, the association of gender, age, religion, care type received, economic status and prognosis of the neurology patients, with the discharge AMA (DAMA) and correlate them with the reasons for DAMA cited by the patients or their relatives.

Material and Methods: In-patients who left AMA between the year 2013 and 2016 ( $\mathrm{n}=689$ ), were prospectively included in the study. Determinants of DAMA and the factors associated with DAMA within eight hours of admission (AMAe; $n=177$ ) were analysed. A pre-AMA questionnaire was completed by those who left AMA after 8 hours (AMAd; $\mathrm{n}=512$ ).

Results: Higher odds of AMA were associated with female gender (OR:1.48), age beyond 50 years (OR:1.35) and admission to intensive care (OR:2.59). Financial constraint was cited as reason of AMAd by the patients with low income (OR:1.72). Higher odds of association of influence of a first degree relative in the decision of AMAd were found in women (OR: 1.33) and persons more than 50 years (OR: 2.95).

Discussion: Women and person older than 50 years had higher risk of DAMA, mostly due to the influence of a first-degree relative. The risk of leaving AMA was significant in those admitted in the neurological intensive care unit. Of all cited reasons of leaving AMA, financial constraint was most significant.

Conclusion: The study provides an insight into the factors for associated with risk of DAMA from neurology wards.
\end{abstract}

\section{Introduction}

The decision of a patient for leaving the hospital against medical advice (AMA)affects the patient management adversely by increasing morbidity, mortality and escalates the cost of treatment. ${ }^{1}$ AMAis a global problem and has been reported from well developed countries as well as developing world. ${ }^{2,3}$ The prevalence of AMA has been shown to vary as per the ethnicity, ${ }^{4}$ socioeconomic status ${ }^{4}$ medical condition ${ }^{5}$ and setting of the study. ${ }^{2,6}$ It also variesbetween teaching and nonteaching hospital. There is paucity of systematic studies looking into the reasons for AMA from India, a country unique in the sense of its deep routed beliefs in alternative medicine, poor penetration of medical insurance, well integrated family structure and high out of pocket health expenditure. Further there is a general belief that in India there exists a bias for the female gender such that they have poor access to health care. $^{7}$ According to the WHO global health expenditure data base, ${ }^{8}$ $89.2 \%$ of the Indian population end up spending out of pocket on health services while only $21.4 \%$ of US population does so. Furthermore there is paucity of literature about the problem of AMA in patients afflicted with neurological ailments. ${ }^{3,6,9}$

We, therefore, envisaged to study the patients being discharged from our wards against medical advice (DAMA) prospectively with an aim to understand how the gender, age, religion, type of care received, economic status and prognosis are linked with the risk of DAMA. Our objective was to further delineate the interrelationship between the above-mentioned determinants and the reasons 'self- reported' by the patients, at the time of leaving AMA.

\section{Material and methods}

\subsection{Site characteristics}

The study was conducted at Department of neurology, Sri Aurobindo Institute of Medical Sciences and PG Institute, Indore. The teaching hospital attached to this medical school is located in the watershed of the rural and urban area and is well equipped with all the

\footnotetext{
* Corresponding author at: 4th Floor, Department of Neurology, Sri Aurobindo Medical College \& P.G. Institute, Sanwer Road, Indore, M.P, India

E-mail address: ajoysodani@yahoo.com (A. Sodani).
} 
modern medical facilities.

In our department, the patients who require constant monitoring are admitted in a well-equipped dedicated neurological intensive care unit which is manned round the clock by a neuro-intensivist, neuro-technicians and neurology trainee residents. Although most of the patients are required to pay out of their pocket for the care, they receive, but the cost is remarkably low as compared with non-teaching hospitals. Furthermore, emergency care, services of the physicians, paramedical staff and food are provided free of cost while the investigations and bed charges are highly subsidized.

\subsection{The cohort}

The patients leaving neurology wards AMA during January 2013 and December 2016 were included in the study $(n=689)$.

A two-staged counseling was applied to every patient. Thereby those who expressed intention to leave our wards AMA were first counseled by one of the investigators (KT) with an aim to make him/her aware of the risks involved. Those adamant on their decision were again counseled discretely, by a paramedic specially trained for the task. This trained person also requested them to fill up the 4 point preAMA questionnaire (Supplementary Annexure 3). All the patients who insisted on leaving AMA were requested to fill up the questionnaire which required a yes/no response to the following four possible causes of DAMA a) financial constraint, b) a compelling social reasons, c) dissatisfaction from treatment and hospital management and d) influence of one of the close blood relatives. In case the patient was not fit to respond, this questionnaire was filled by their first-degree relative.

None of the investigators were aware of the responses of the patients to the given questionnaire until January 2017, when the data compilation and analysis began. The demographic data, type of care received and prognosis explained at the time of admission of all the admitted patients in neurology department $(n=4622)$ during the study period, was extracted from the hospital medical records and filled in the study proforma. The questionnaire forms were reviewed. The reasons for leaving AMA were noted and grouped according to their response to pre AMA questionnaire, henceforth called 'self reported reasons of DAMA'(SRR).

The economic status and the area of the residence of the patients leaving hospital AMA was deduced from the information provided at the time of admission to the hospital. One of the investigators (ANK) entered the clinical data in the study proforma.

\subsection{Data management}

The patients were grouped as per the length of stay in the wards prior to leaving AMA into AMAe and AMAd, age (less/more than 50 years), gender (male/female), religion (Hindu/Non- Hindu), type of care received at the time of AMA (intensive care/non-intensive care), and pre AMA prognosis as explained by admitting physician (threat to life/no threat to life). The patients who filled up the pre-AMA questionnaire $(n=512)$ were grouped, in addition to above, according to their economic status (LIG/OIG) and area of residence (rural/urban).

\section{Definitions}

1. Non-Hindu: belief in a religion other than Hindu (Muslim, Sikh, Christian).

2. Urban area: all places with a municipality, corporation, Cantonment Board or notified town area committee as per census $2011 .^{10}$

3. Rural areas: were the ones which are not categorized as an urban area in Census 2011. ${ }^{10}$

4. Low-income group (LIG): those engaged in a non-agriculture job in a rural area; blue-collar job, daily wager and class IV worker. ${ }^{11}$

5. Other income group (OIG): white collared jobs; school teachers; small family business; rural inhabitants with the permanent address (house owners); Class II/III worker; and all others with HighIncome group and with Pucca house. ${ }^{11}$

6. The threat to life: When a prognosis of "impending threat to life" was pronounced. Following conditions were judged to have a threat to life a) comatose patients because of structural brain lesions, CNS infections or metabolic causes b) patients with neuromuscular diseases requiring mechanical ventilation and c) those with refractory status epilepticus.

7. Financial constraint: when there was self-declaration of financial problems or were not able to procure necessary medications due to lack of funds or refused life supports citing financial reasons.

8. Compelling social reasons: Harvesting season, social functions, fear of loss of the job or loss of wages or lack of family support for the necessary continuation of treatment.

9. Dissatisfaction: when patient or attendees were not satisfied with the hospital services, physician, and paramedical staff.

10. First degree relatives: spouse, son, daughter, and parents of the patient.

\section{Exclusions}

Those who expired were excluded from the analysis $(n=154)$.

\section{Statistical analysis}

The overall risk for leaving AMA was determined according to gender, age, religion and type of care received. The factors associated with higher odds of early AMA were analyzed. The association of the responses filled in the pre AMA questionnaire with the gender, economic status and prognosis were analyzed. Differences between the determinants of AMAe and AMAd were sought.

The statistical analysis was done using free online software (Graph $\mathrm{PAD}^{12}$ and MedCalc ${ }^{13}$ ) and Microsoft Excel 2010. ${ }^{14}$ Categorical variables were presented as a percentile. The relationship between the variables and outcome was calculated using relative risk (RR) was calculated at $95 \%$ confidence interval (CI) by drawing a ' $2 \times 2$ contingency table'. The odds of increased chances of AMA were determined by calculating the Odd ratio (OR) by Altman test. As and when required the significance level was evaluated further with two-tailed Fisher's exact test or comparison of proportions. The significance level was set at $\mathrm{RR}>1$ and two-tailed $\mathrm{p} \leq 0.05$ and $\mathrm{OR}>1$.The study was approved by institutional scientific and research committee.

\section{Results}

During the study period, 4622 patients were admitted in our department, of which 689 (14.9\%) patients left our wards AMAand were enrolled prospectively in the study (Fig. 1). The summary of the discharge pattern of the patients and the demographic variables is provided in Table 1.

In our cohort of AMA group there exists a subgroup which leave within few hours of reaching the hospital, most of the time even before a proper diagnostic algorithm and appropriate treatment strategy could be formulated thus rendering the counseling of such patients difficult. Out of 689 AMA patients, we could identify 177 (25.7\%) left hospital within 8 hours of admission (AMAe), and pre-AMA questionnaire could not be filled for them.

$74.3 \%$ of $689(n=512)$ continued with the prescribed therapy beyond 8 hours of admission before leaving hospital AMA (AMA), underwent 2 staged counseling and filled up the pre-AMA questionnaire. Higher odds of AMA were associated with female gender (OR:1.48, 95\% CI:1.26-1.75), age beyond 50 years (OR:1.35, 95\% CI:1.14-1.59), non Hindu (OR:1.65, 95\% CI:1.30-2.1), those admitted in intensive care (OR:2.59, 95\% CI:2.19-3.07).

Determinants of early AMA are summarized in Table 2.The odds of 


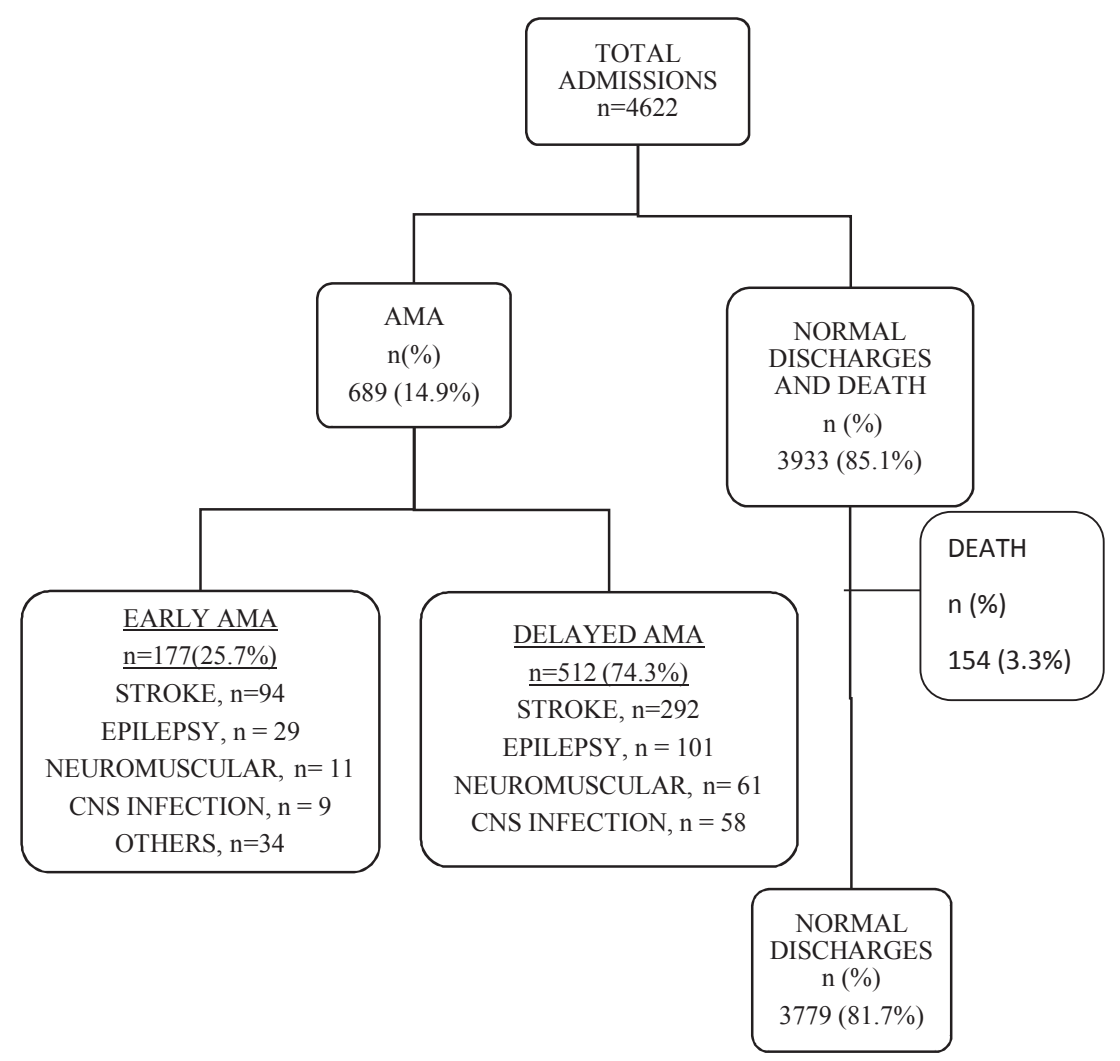

Fig. 1. Distribution of total study patients.

leaving hospital within few hours of admission are significantly associated with female gender (OR:1.52, 95\% CI:1.08-2.15) and non-Hindu (OR:1.41, 95\% CI:0.88-2.24). Our result shows that the age of patient did not influence the decision to take patient AMAe, while admission to the intensive care unit had marginally higher odd for AMAe (OR:1.12, 95\% CI:0.78-1.6). AMAe was not associated with either the prognosis of the patient and the economic status.

The financial constraint was cited as the reason for leaving AMAd by $61.1 \%$ (313 of 512).The decision of AMA was taken due to the influence and interference of first degree relatives in $82 \%$ of patients (420 of 512). Compelling social reasons were cited as the reason for leaving AMAd by only $17 \%$ of patients ( 87 of 512 ), and dissatisfaction was not a significant reason for leaving AMAd with only 8\% (41 of 512) leaving AMA because of this reason (Table 3).

The interrelationship between the gender, age, religion, care type economic status and prognosis of the patient with SRR was further analyzed, and results are summarized in tables 4-9.

Out of 512 AMAd patients, $39.45 \%$ belonged to the group who were given a grave prognosis, as against $60.55 \%$ (310 of 512) belonging to 'no threat to life' group. We did not find any of the SRR to be associated with prognosis (Table 4, panel E).

Dissatisfaction and religion showed a weak association with the slightly high percentage of non-Hindu leaving AMA citing dissatisfaction as a cause of AMA (9\% vs. 7.9\%, OR:1.15, 95\% CI:0.46-2.8) (Tables 4 and 5, panel C). Gender, age, economic status and care type received were not significantly associated with dissatisfaction (Table 5, panel A, B, D \& F). However, it is worth noticing that higher number of males, persons with higher income and those who did not have a threat to life reported dissatisfaction (Table 4, panel A, D \& F).

Financial constraint was more frequently cited as the reason of AMAd by the patients belonging to low income group (67.9\% vs $55 \%$, OR:1.72, 95\% CI:1.2-2.48) (Tables 4 and 5, panel D) but did not turn

Table 1

Discharge pattern of the patients admitted in the neurology department between January 2013-December 2016 ( $\mathrm{n}=4468$ ).

\begin{tabular}{|c|c|c|c|c|c|c|}
\hline \multirow[t]{2}{*}{ Variables } & \multirow[t]{2}{*}{ Sub groups n (\%) } & \multirow[t]{2}{*}{$\mathrm{AMA}^{\mathrm{a}} \mathrm{n}(\%) 689(15.4)$} & \multirow[t]{2}{*}{$\mathrm{ND}^{\mathrm{b}} \mathrm{n}(\%) 3779(84.6)$} & \multicolumn{3}{|l|}{ Significance } \\
\hline & & & & $\mathrm{RR}(95 \% \mathrm{CI})^{*}$ & OR $(95 \% \mathrm{CI})^{\mathrm{c}}$ & $P$ value ${ }^{d}$ \\
\hline \multirow[t]{2}{*}{ Gender } & Female 1663(37.2) & $312(18.8)$ & $1351(81.2)$ & $1.39(1.21-1.6)$ & $1.48^{\mathrm{S}}(1.26-1.75)$ & $<0.0001^{\mathrm{s}}$ \\
\hline & Male 2805(62.8) & $377(13.4)$ & $2428(86.6)$ & & & \\
\hline \multirow[t]{2}{*}{ Age } & $<502191(49)$ & $294(13.4)$ & $1897(86.6)$ & $1.29(1.12-1.48)$ & $1.35^{\mathrm{S}}(1.14-1.59)$ & $=0.0003^{\mathrm{S}}$ \\
\hline & $>502277(51)$ & $395(17.3)$ & $1882(82.7)$ & & & \\
\hline \multirow[t]{2}{*}{ Religion } & Hindu 4026(90.1) & $591(14.7)$ & 3435 (85.3) & $1.51(1.24-1.82)$ & $1.65^{\mathrm{S}}(1.30-2.10)$ & $<0.0001^{\mathrm{s}}$ \\
\hline & Non-Hindu 442(9.9) & $98(22.2)$ & $344(77.8)$ & & & \\
\hline \multirow[t]{2}{*}{ Care type } & Intensive care $1983(44.4)$ & $442(22.3)$ & $1541(77.7)$ & $2.24(1.94-2.59)$ & $2.59^{\mathrm{S}}(2.19-3.07)$ & $<0.0001^{\mathrm{s}}$ \\
\hline & Non intensive care $2485(55.6)$ & $247(9.9)$ & $2238(90.1)$ & & & \\
\hline
\end{tabular}

S = Significant; NS = Not significant.

${ }^{\text {a }}$ AMA (Against medical advice).

${ }^{\mathrm{b}}$ normal discharge.

c Done by Altman test.

${ }^{\mathrm{d}}$ Done by two tailed Fischer exact test. 
Table 2

Determinants of leaving early AMA (AMAe).

\begin{tabular}{|c|c|c|c|c|}
\hline \multirow[t]{2}{*}{ Variables } & \multirow[t]{2}{*}{ Groups n } & \multicolumn{2}{|l|}{ AMA $n=689$} & \multirow{2}{*}{$\begin{array}{l}\text { Significance } \\
\text { OR }(95 \% \mathrm{CI})^{\mathrm{a}}\end{array}$} \\
\hline & & $\begin{array}{l}\text { AMAe, } \mathrm{n}(\%) \\
\mathrm{n}=177 \\
(25.7 \%)\end{array}$ & $\begin{array}{l}\text { AMAd }^{\mathrm{b}} \mathrm{n}(\%) \\
\mathrm{n}=512 \\
(74.3 \%)\end{array}$ & \\
\hline \multirow[t]{2}{*}{ Gender } & Female 312 & $94(30.1)$ & 218 (69.9) & $1.52(1.08-2.15)^{\mathrm{S}}$ \\
\hline & Male 377 & $83(22)$ & $294(78)$ & \\
\hline \multirow[t]{4}{*}{ Age } & $<50$ & $73(24.8)$ & $221(75.2)$ & $1.08(0.76-1.53)^{\mathrm{NS}}$ \\
\hline & 294 & & & \\
\hline & $>50$ & $104(26.3)$ & $291(73.7)$ & \\
\hline & 395 & & & \\
\hline \multirow[t]{2}{*}{ Religion } & Hindu 591 & $146(24.7)$ & $445(75.3)$ & $1.41(0.88-2.24)^{\mathrm{S}}$ \\
\hline & $\begin{array}{l}\text { Non-Hindu } \\
98\end{array}$ & $31(31.6)$ & $67(68.4)$ & \\
\hline \multirow[t]{2}{*}{ Care type } & $\begin{array}{l}\text { Intensive } \\
\text { care } 442\end{array}$ & $117(26.5)$ & $325(73.5)$ & $1.12(0.78-1.6)^{\mathrm{S}}$ \\
\hline & $\begin{array}{l}\text { Non } \\
\text { intensive } \\
\text { care } 247\end{array}$ & $60(24.3)$ & $187(75.7)$ & \\
\hline Threat to & Yes 269 & $67(24.9)$ & $202(75.1)$ & $0.93(0.65-1.32)^{\mathrm{NS}}$ \\
\hline life & No 420 & $110(26.2)$ & $310(73.8)$ & \\
\hline Economic & LIG 306 & $63(20.6)$ & $243(79.4)$ & $0.61(0.42-0.87)^{\mathrm{NS}}$ \\
\hline status & OIG 383 & $114(29.8)$ & $269(70.2)$ & \\
\hline
\end{tabular}

$\mathrm{S}=$ Significant; NS = Not significant.

a Done by Altman test.

b Delayed AMA.

Table 3

Self reported reasons for AMAd $(\mathrm{n}=512)$.

\begin{tabular}{lll}
\hline Reason & Response & $\mathrm{n}(\%)$ \\
\hline Financial constraint & Yes & $313(61.1)$ \\
& No & $199(38.9)$ \\
Compelling social reason & Yes & $87(17)$ \\
Dissatisfaction & No & $425(83)$ \\
Influenced by a first degree relative & Yes & $41(8)$ \\
& No & $471(92)$ \\
& Yes & $420(82)$ \\
& No & $92(18)$ \\
\hline
\end{tabular}

out to be a risk associated with AMAd from the perspective of gender, age, religion, type of care received and prognosis (Table 5, panel A-C, E \& F).

Odds of association of influence of a first degree relative in the execution of the decision of AMAd were significantly high in women (OR: 1.33, 95\% CI: 0.83-2.11) (Table 5, panel A). Persons aged more than 50 years had higher odds of getting influenced by a first degree relative in deciding on taking AMAd (OR: 2.95, 95\% CI:1.36-3.4) (Table 5, panel B).

\section{Discussion}

This prospective study highlights thepattern and determinants of neurological patients leaving AMA from a teaching hospital located in a semi-urban area. The prevalence of DAMA (14.9\%) in our cohort seems to be high at first glance. The prevalence of DAMA appears to depend upon several factors. Emergency department-based study from a private hospital in India has reported the rate of AMA to be $3.84 \%,{ }^{6}$ in the patients with asthma the rate of AMA was found to be $4.94 \%,{ }^{15}$ and that from a psychiatry ward was $8 \%{ }^{16}$ while in orthopedic patients it was reported to be $13.9 \%{ }^{17}$

Our study provides, to best of our knowledge, the largest cohort of pure neurological patients leaving AMA. We looked into the published data using AMA, DAMA and leave against medical advice as key words. We found 37 studies; after reviewing their abstracts; 17 were excluded for following reasons - pediatric population $(n=9)$; review articles $(n=4)$; assessing readmission rates $(n=1)$; insufficient data $(n=1)$; physicians role in preventing AMA $(n=2)$. Out of the remaining 20 studies; spread between 1962-2016; 15 originated from the developed countries while the remaining belonged to developing countries. 14 of these were conducted in teaching institutes while remaining 6 were from the non-teaching institutes but none of the studies comprised of a pure neurological cohort (Supplementary Annexure 1 and 2).

In contrast to earlier studies from the western world, who reported male gender to be at risk of AMA, ${ }^{2,9,18,19}$ we found women to be at risk of leaving AMA. This difference could have arisen because of the differences in the patient characteristics. The studies from the western researchers included patients with alcohol dependence and substance abuse, a problem found to be prevalent in men because of social, cultural and biological reasons. ${ }^{20-22}$ Furthermore, the prevalence of drug and substance abuse in the geographical area, which our hospital caters to, is low. ${ }^{23}$ In agreement with the work of Naderi et al., ${ }^{6}$ we found that the women decide of leaving hospital AMA under influence of the firstdegree relative. However, our findings do not agree with Thomson Reuter $^{7}$ who suggested that women are vulnerable to poor access to health services as they are viewed as an economic burden to the society. We specifically explored in this direction, and our data found no statistical association between the gender of the persons leaving AMA and financial constraints.

The studies from the western world have reported up to two-fold higher risk in the minority religion groups ${ }^{24}$ and blacks. ${ }^{9,25}$ In our study higher odds for DAMA emerged for the non-Hindus (minority religion group). Daniel RS et al. ${ }^{4}$ also found links between religion and higher

Table 4

Descriptive statistics SRR vs risk factors.

\begin{tabular}{|c|c|c|c|c|c|c|c|c|c|}
\hline & \multirow[t]{2}{*}{ Variable } & \multicolumn{2}{|c|}{ Compelling socialreason } & \multicolumn{2}{|c|}{ Dissatisfaction } & \multicolumn{2}{|c|}{ Financial constraint } & \multicolumn{2}{|c|}{ Influence by a first degree relative } \\
\hline & & Yes n (\%) & No n $(\%)$ & Yes n (\%) & No $n(\%)$ & Yes n (\%) & No n $(\%)$ & Yes n (\%) & No n (\%) \\
\hline \multirow[t]{2}{*}{ A } & Female $n(\%) n=218(100 \%)$ & $36(16.5)$ & $182(83.5)$ & $15(6.9)$ & $203(93.1)$ & $130(59.6)$ & $88(40.4)$ & $184(84.4)$ & $34(15.6)$ \\
\hline & Male $n(\%) n=294(100 \%)$ & $51(17.3)$ & $243(82.7)$ & $26(8.8)$ & $268(91.2)$ & $183(62.2)$ & $111(37.8)$ & $236(80.3)$ & $58(19.7)$ \\
\hline \multirow[t]{2}{*}{ B } & $>50 \mathrm{n}(\%) \mathrm{n}=291(100 \%)$ & $54(18.6)$ & $237(81.4)$ & $23(7.9)$ & $268(92.1)$ & $168(57.7)$ & $123(42.3)$ & $253(86.9)$ & $38(13.1)$ \\
\hline & $<50 \mathrm{n}(\%) \mathrm{n}=221(100 \%)$ & $33(14.9)$ & $188(85.1)$ & $18(8.1)$ & $203(91.9)$ & $145(65.6)$ & $76(34.4)$ & $167(75.6)$ & $54(24.4)$ \\
\hline \multirow[t]{2}{*}{ C } & non Hindu $n(\%) n=67(100 \%)$ & $10(14.9)$ & $57(85.1)$ & $6(9)$ & $61(91)$ & $35(52.2)$ & $32(47.8)$ & $52(77.6)$ & $15(22.4)$ \\
\hline & Hindu $\mathrm{n}(\%) \mathrm{n}=445(100 \%)$ & $77(17.3)$ & $368(82.7)$ & $35(7.9)$ & $410(92.1)$ & $278(62.5)$ & $167(37.5)$ & $368(82.7)$ & $77(17.3)$ \\
\hline \multirow[t]{2}{*}{$\mathrm{D}$} & $\mathrm{LIG}^{\mathrm{a}} \mathrm{n}(\%) \mathrm{n}=243(100 \%)$ & $34(13.9)$ & $209(86.1)$ & $17(6.9)$ & $226(93)$ & $165(67.9)$ & $78(32.1)$ & $197(81.1)$ & 46 (18.9) \\
\hline & $\mathrm{OIG}^{\mathrm{b}} \mathrm{n}(\%) \mathrm{n}=269(100 \%)$ & $53(19.7)$ & $216(80.3)$ & 24 (8.9) & $245(91)$ & $148(55)$ & $121(45)$ & $223(82.9)$ & $46(17.1)$ \\
\hline \multirow[t]{2}{*}{ E } & Threat to life $n(\%) n=202(100 \%)$ & $18(8.9)$ & $184(91.1)$ & $11(5.4)$ & $191(94.6)$ & $123(60.9)$ & $79(39.1)$ & $158(78.2)$ & $44(21.8)$ \\
\hline & No Threat to life $n(\%) n=310(100 \%)$ & $69(22.2)$ & $241(77.7)$ & $30(9.6)$ & $280(90.4)$ & $190(61.3)$ & $120(38.7)$ & $262(84.5)$ & $48(15.5)$ \\
\hline \multirow[t]{2}{*}{$\mathrm{F}$} & Intensive care $\mathrm{n}(\%) \mathrm{n}=325(100 \%)$ & $42(12.9)$ & $283(87.1)$ & $23(7.1)$ & $302(92.9)$ & $200(61.5)$ & $125(38.5)$ & $259(79.7)$ & $66(20.3)$ \\
\hline & Non intensive care $n(\%) n=187(100 \%)$ & $45(24.1)$ & $142(75.9)$ & $18(9.6)$ & $169(90.4)$ & $113(60.4)$ & $74(39.6)$ & $161(86.1)$ & $26(13.9)$ \\
\hline
\end{tabular}

\footnotetext{
${ }^{\text {a }}$ LIG: Low income group.
}

b OIG: Other income group. 
Table 5

Correlation of variables.

\begin{tabular}{|c|c|c|c|c|c|}
\hline & Risk factor & $\begin{array}{l}\text { Compelling social reason OR }(95 \% \\
\text { CI) }\end{array}$ & Dissatisfaction OR ( $95 \% \mathrm{CI})$ & $\begin{array}{l}\text { Financial constraint OR }(95 \% \\
\text { CI) }\end{array}$ & $\begin{array}{l}\text { Influenced by a first degree relative OR } \\
(95 \% \mathrm{CI})\end{array}$ \\
\hline A & Gender & $0.94^{\mathrm{NS}}(0.59-1.5)$ & $0.76^{\mathrm{NS}}(0.39-1.47)$ & $0.89^{\mathrm{NS}}(0.62-1.28)$ & $1.33^{\mathrm{S}}(0.83-2.11)$ \\
\hline B & Age & $1.29^{\mathrm{S}}(0.80-2.08)$ & $0.96^{\mathrm{NS}}(0.50-1.84)$ & $0.71^{\mathrm{NS}}(0.49-1.02)$ & $2.15^{\mathrm{S}}(1.36-3.4)$ \\
\hline $\mathrm{C}$ & Religion & $0.83^{\mathrm{NS}}(0.41-1.71)$ & $1.15^{\mathrm{S}}(0.46-2.8)$ & $0.65^{\mathrm{NS}}(0.39-1.10)$ & $0.72^{\mathrm{NS}}(0.38-1.35)$ \\
\hline $\mathrm{D}$ & Economic Status & $0.66^{\mathrm{NS}}(0.41-1.06)$ & $0.76^{\mathrm{NS}}(0.40-1.46)$ & $1.72^{\mathrm{S}}(1.20-2.48)$ & $0.88^{\mathrm{NS}}(0.56-1.38)$ \\
\hline $\mathrm{E}$ & Threat to life (prognosis) & $0.34^{\mathrm{NS}}(0.19-0.59)$ & $0.5^{\mathrm{NS}}(0.26-1.09)$ & $0.89^{\mathrm{NS}}(0.68-1.41)$ & $0.65^{\mathrm{NS}}(0.4-1.03)$ \\
\hline $\mathrm{F}$ & Care type & $0.46^{\mathrm{NS}}(0.29-0.74)$ & $0.71^{\mathrm{NS}}(0.37-1.36)$ & $1.04^{\mathrm{NS}}(0.72-1.51)$ & $0.63^{\mathrm{NS}}(0.38-1.03)$ \\
\hline
\end{tabular}

OR calculated according to Altman Test; S = significant; NS = Non-significant.

AMA rates, with more Catholics and Jews leaving AMA than Protestants.

Association between old age and higher odds of DAMA has been documented in the past ${ }^{3,18,22}$ Lelieveld $\mathrm{C}$ et al. ${ }^{26}$ found a trend of increased DAMA in older patients aged more than 65 years and attributed it to poor socioeconomic status. In our cohort, those aged beyond 50 years had significantly higher risk of DAMA, and they did so due to the influence of a close relative and also gave compelling social reason as a cause of AMAd. Although this could mean apathy towards the aged persons but other, more plausible, reason appears to be the Indian family structure, where the presence of elderly is almost quintessential for any social or auspicious ceremony.

We, like Baptist et al. ${ }^{15}$ have found that the risk of leaving AMA was significant in those admitted in the intensive care unit.

Out of theSRR for DAMA, the financial constraint, emerged as themajor reason for DAMA after the influence of close relatives. The financial constrainthas been reported to be the main reason forcing DAMA, from countries other than ours. ${ }^{2,3,6,9}$

In India relatives and friendsare theprimary source of emotional, physical and psychological support for ailing persons. They are activelyinvolved in health related decision making of patients as well. Our result further emphasize the above stated social functioning, wherein involvement of a first degree relative in forcing DAMA decision in $81.5 \%$ of the cases emerged as the key factor leading to DAMA. Naderi et al. ${ }^{6}$ also found that in $65 \%$ cases family members decided to leave hospital against medical advice.

Strengths of our study are a large cohort of neurological in-patients and prospective study design.

Although the sizeable number of DAMA patients left AMAe (25.7\%) but operational constraints didnotallow collection of data about the reasons for their decision. Logically the financial, social and genderspecific reasons should not come into play so early after admission, particularly in our institute which offers free of charge emergency care for first 24 hours. The reasons for leaving AMA in this group needs to be explored further.

\section{Conclusion}

Leaving AMA rates are high in neurological in-patients. DAMA was higher in old age, female gender, minority groups and intensive care receiving patients. Financial constraint was the major reason for taking patient DAMA. Influence of first degree relative in taking the decision to take patient AMA was the major determinant for female gender as well as the older people. Compelling social reason was an additional factor that played a significant role in leaving AMA by the older people.

We believe that, although subject to validation by multicenter studies, findings of our study would help health care providers in, a) developing a counseling algorithm with focused methods to sensitize the relatives about the risks of leaving hospital AMA and, b) finding ways to arrange financial help for those in need while also sensitizing society towards the need for medical insurance.

\section{Ethical publication statement}

We confirm that we have read the Journal's position on issues involved in ethical publication and affirm that this report is consistent with those guidelines.

\section{Conflicts of interest}

None of the authors has any conflict of interest to disclose.

\section{Financial disclosure}

None of the authors has relevant financial relationships to disclose. This research did not receive any grant from funding agencies in the public, commercial, or not-for-profit sectors.

\section{Contributorship}

All the authors have contributed to the conception and design of the study, analysis and interpretation of data and drafting the manuscript.

\section{Declaration of originality}

This is an original work and has not been published in whole or part, in any print or electronic media or is under consideration of publication in any print or electronic media.

\section{Compliance with ethical guidance}

All procedures were followed in accordance with the Sri Aurobindo Medical College \& P.G. Institute's committee on human experimentation and with Helsinki Declaration of 1975 and subsequent revisions.

\section{Acknowledgement:}

The authors acknowledge Prof. Richa Nigam, Department of Community Medicine, Sri Aurobindo Medical College \& P.G. Institute for her contribution in preparation of statistical data.

\section{Appendix A. Supplementary data}

Supplementary data associated with this article can be found, in the online version, at https://doi.org/10.1016/j.cegh.2018.02.011.

\section{References}

1. Alfandre DJ. I'm going home: discharges against medical advice. Mayo Clinic Proc. 2009;84(March (3)):255-260 Elsevier.

2. Weingart SN, Davis RB, Phillips RS. Patients discharged against medical advice from a general medicine service. J Gen Intern Med. 1998;13(August (8)):568-571.

3. Fadare JO, Babatunde OA, Olanrewaju T, Busari O. Discharge against medical advice: experience from a rural Nigerian hospital. Ann Niger Med. 2013;7(July (2)):60.

4. Daniels RS, Margolis PM, Carson RC. Hospital discharges against medical advice: I: origin and prevention. Arch Gen Psychiatry. 1963;8(February (2)):120-130.

5. Withersty DJ. Patient responsibility and the AMA discharge: a one-year follow-up 
study. Am J Psychiatry. 1977;134(12):1442-1444.

6. Naderi S, Acerra JR, Bailey K, et al. Patients in a private hospital in India leave the emergencydepartment against medical advice for financial reason. Int J Emerg Med. 2014;7(December (1)):13.

7. India Fourth Most Dangerous Country for Women: Poll. [http://archive. indianexpress.com/news/india-fourth-most-dangerous-country-for-women-poll/ 803716/].

8. Out of Pocket Health Expenditure (\% of Private Expenditure on Health). https://data. worldbank.org/indicator/SH.XPD.OOPC.TO.ZS.

9. Glasgow JM, Vaughn-Sarrazin M, Kaboli PJ. Leaving against medical advice (AMA): risk of 30-day mortality and hospital readmission. J Gen Intern Med. 2010;25(September (9)):926-929.

10. http://censusindia.gov.in/Data_Products/Library/Indian_perceptive_link/Census_ Terms_link/censusterms.html.

11. http://secc.gov.in/categorywiseIncomeSourceReport?reportType =All \%20Category\#

12. https://www.graphpad.com/quickcalcs/.

13. https://www.medcalc.org/statistics.php.

14. https://products.office.com/en-in/office-online/documents-spreadsheetspresentations-office-online.

15. Baptist AP, Warrier I, Arora R, Ager J, Massanari RM. Hospitalized patients with asthma who leave against medical advice: characteristics, reasons, and outcomes. $J$ Allergy Clin Immunol. 2007;119(April (4)):924-929.

16. Pages KP, Russo JE, Wingerson DK, Ries RK, Roy-Byrne PP, Cowley DS. Predictors and outcome of discharge against medical advice from the psychiatric units of a general hospital. Psychiatric Serv. 1998;49(September (9)):1187-1192.

17. Poppola SO, Onyemaechi NO, Kortor JN, Oluwadiya KS. Leave against medical advice (LAMA) from in patient orthopedic treatment. SA Orthopedic $J$. 2013;12(September (3)):58-61

18. Lee CA, Cho JP, Choi SC, Kim HH, Park JO. Patients who leave the emergency department against medical advice. Clin Exp. Emerg Med. 2016;3(2):88-94.

19. Kraut A, Fransoo R, Olafson K, Ramsey CD, Yogendran M, Garland A. A populationbased analysis of leaving the hospital against medical advice: incidence and associated variables. BMC Health Serv Res. 2013;13(October (1)):415.

20. https://www.samhsa.gov/data/sites/default/files/NSDUH-DetTabs2014/NSDUHDetTabs2014.pdf.

21. Murthy P, Manjunatha N, Subodh BN, Chand PK, Benegal V. Substance use and addiction research in India. Indian J Psychiatry. 2010;52(January (Suppl. 1)):S189.

22. Holmila M, Raitasalo K. Gender differences in drinking: why do they still exist? Addiction. 2005;100(December (12)):1763-1769.

23. http://www.unodc.org/pdf/india/presentations/india_national_survey_2004.pdf.

24. Daniels RS, Margolis PM, Carson RC. Hospital discharges against medical advice: I: origin and prevention. Arch Gen Psychiatry. 1963;8(February (2)):120-130.

25. Franks P, Meldrum S, Fiscella K. Discharges against medical advice: are race/ethnicity predictors? J Gen Intern Med. 2006;21:955-960.

26. Lelieveld C, Leipzig R, Gaber-Baylis LK, et al. Discharge against medical advice of elderly inpatients in the United States. J Am Geriatrics Soc. 2017;65(September (9)):2094-2099. 